\title{
Interactions of Gallic Acid with Porcine Hemoglobin: Effect on the Redox State and Structure of Hemoglobin
}

Jingwen Dong, ${ }^{\dagger, l}$ Xueli Li, ${ }^{\ddagger}, \|$ Yaoqing Zhou, ${ }^{\dagger}$ Yunhao Lu, ${ }^{\dagger}$ Yuanping Lv, ${ }^{*}{ }^{\dagger}$ Yuanlong Chi, ${ }^{\dagger}$ Qiang $\mathrm{He}^{*}, \dagger$

${ }^{\dagger}$ College of Biomass Science and Engineering, Sichuan University, Chengdu 610065, $P$.

R. China

†Department of Inspection, Chengdu Medical College, Chengdu 610101, P. R. China

*Email: 1vyuanping@scu.edu.cn. Phone: +86-28-85405236.

*Email: heq361@163.com. Phone: +86-28-85405236. 


\section{Content:}

Figure S1. Amount of free iron released from $\mathrm{Hb}$ in the absence and presence of GA after $24 \mathrm{~h}$ oxidation at $\mathrm{pH} 4.5,25^{\circ} \mathrm{C}$. Hb concentration was $75 \mu \mathrm{M}$. GA concentrations were $40,75,150$, and $320 \mu \mathrm{M} . * \mathrm{p}<0.05$.

Figure S2. Relative fluorescence intensity of Hb-ANS mixtures with addition of GA $(40,75,150$, and $320 \mu \mathrm{M})$ at $\mathrm{pH} 7.4,25^{\circ} \mathrm{C}$.

Table S1. Fractions of secondary structures of $\mathrm{Hb}$ in the absence and presence of GA at $\mathrm{pH} 7.4,25^{\circ} \mathrm{C}$. 


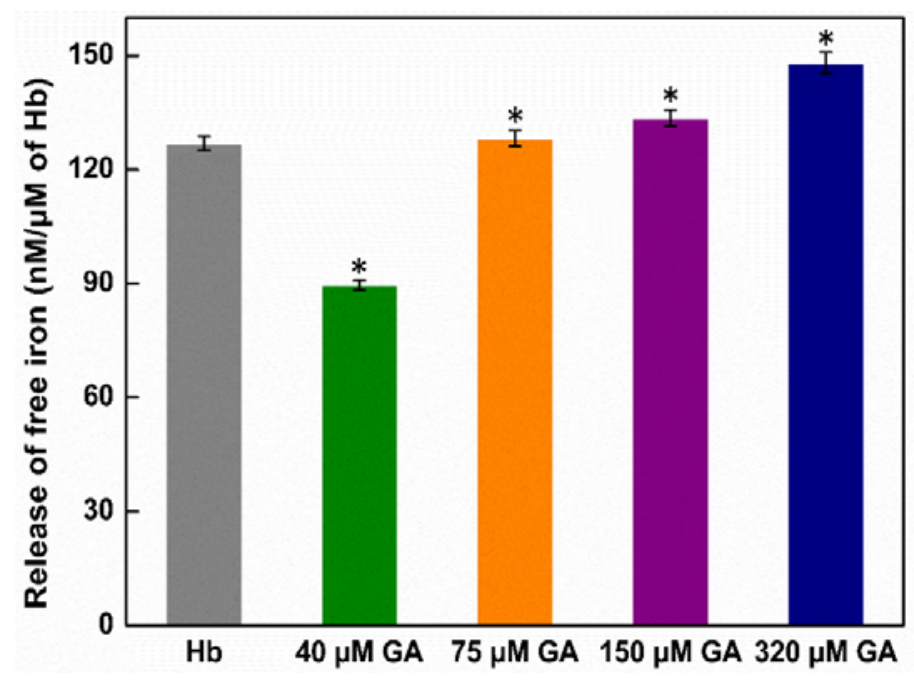

Figure S1. Amount of free iron released from $\mathrm{Hb}$ in the absence and presence of GA after $24 \mathrm{~h}$ oxidation at $\mathrm{pH} 4.5,25^{\circ} \mathrm{C}$. Hb concentration was $75 \mu \mathrm{M}$. GA concentrations were $40,75,150$, and $320 \mu \mathrm{M} . * \mathrm{p}<0.05$. 


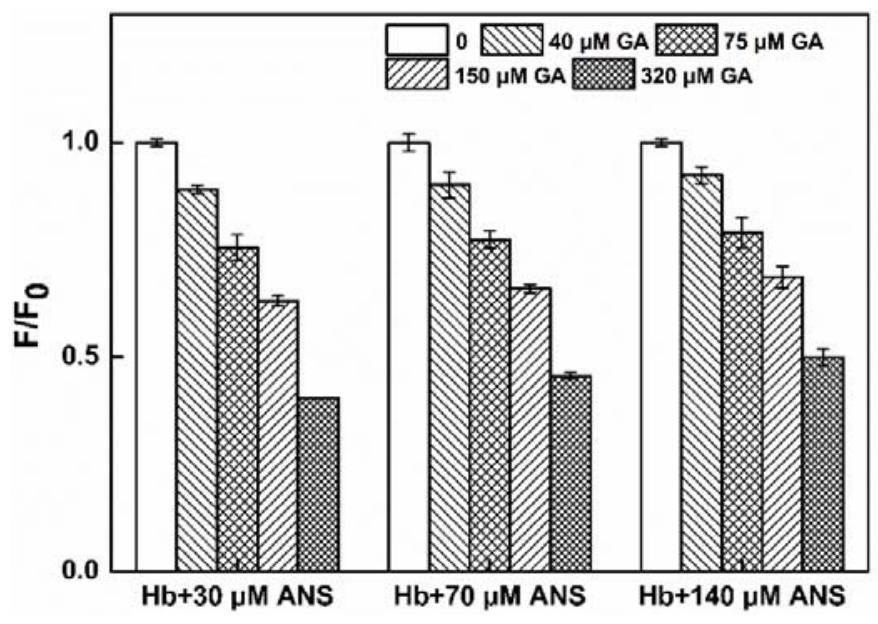

Figure S2. Relative fluorescence intensity of $\mathrm{Hb}$-ANS mixtures with addition of GA $(40,75,150$, and $320 \mu \mathrm{M})$ at $\mathrm{pH} 7.4,25^{\circ} \mathrm{C}$. 


\section{Table S2}

Fractions of secondary structures of $\mathrm{Hb}$ in the absence and presence of $\mathrm{GA}$ at $\mathrm{pH} 7.4$, $25^{\circ} \mathrm{C}$

\begin{tabular}{ccccc}
\hline & $\alpha$-helix $\%$ & $\beta$-sheet $\%$ & $\beta$-turn $\%$ & Unordered\% \\
\hline $\mathrm{Hb}$ & 77.87 & 0.67 & 6.51 & 14.94 \\
$\mathrm{Hb}+40 \mu \mathrm{M} \mathrm{GA}$ & 75.97 & 0.84 & 7.67 & 15.51 \\
$\mathrm{Hb}+75 \mu \mathrm{M} \mathrm{GA}$ & 73.36 & 1.64 & 8.88 & 16.12 \\
$\mathrm{Hb}+150 \mu \mathrm{M} \mathrm{GA}$ & 65.96 & 3.67 & 12.09 & 18.27 \\
$\mathrm{Hb}+320 \mu \mathrm{M} \mathrm{GA}$ & 56.44 & 5.05 & 16.63 & 21.88 \\
\hline
\end{tabular}

